\title{
On the timing of managed funds' industry exposure
}

\author{
Julia Sawicki $\mathrm{a}^{*}$ \\ a Nanyang Business School, Nanyang Technological University. \\ *Corresponding author's email address: julia.sawicki@dal.ca
}

\section{A R T I C L E I N F O}

Received: 03-11-2016

Accepted: 07-12-2016

Available online: 15-01-2017

Keywords:

Managed funds;

Market timing;

Performance evaluation;

Sector rotation.

A B S T R A C T

An important source of performance for active managers is industry weighting, yet this is neglected by the performance evaluation literature. Most market timing studies are conducted at a broad level, assessing exposure to equities as an asset class. This paper investigates the ability of US equity fund managers to time industry performance. The results indicate that, as a group, the funds exhibit no timing skills, with positive timing as frequent as negative timing. There is a subset of funds however, that appear to have strong forecasting abilities, correctly timing industries that are otherwise poorly timed by most fund managers. General timing ability is weakest in the Finance, Cyclical Services and Information Technology industries, while Consumer Goods industries show the best timing results.
\end{abstract}

JEL Classification : G23 ; L0.

(C) 2017 The Authors. This is an open access article under the terms of the Creative Commons Attribution License 4.0, which allows use, distribution and reproduction in any medium, provided the original work is properly cited.

\section{Introduction}

"Some favorable industry positioning also played a role in the fund's success (over the period). Overweighting energy, the benchmark's best-performing sector of the past six months, was a key strategy."

$$
\text { Robert Stansky, Manager Fidelity }{ }^{\circ} \text { Magellan }{ }^{\circ} \text { Fund }^{1}
$$

Studies of managed fund performance abound, where an array of techniques and data are applied in assessing fund manager stock-picking or market timing skill. The results do not paint an impressive picture: as a group, active managers are not able to deliver returns more than their lower-cost index counterparts.

This study addresses a gap in this vast literature. Most studies of market timing are conducted at the broad asset class level, measuring the ability to change exposure to equities to participate in up markets and avoid down markets. In this paper, we take the investigation to a deeper level. An important part of the equity fund asset allocation decision occurs at the industry level. As illustrated by the quote of the manager of the largest actively managed funds in the United States, Fidelity Magellan, industry exposure is an important factor. This observation is typical of comments made by fund managers in discussing performance and assessing strategy. More elaborate is the response of another equity fund manager to the question: "How did the fund's positioning evolve since the shareholder update six months ago?"

\footnotetext{
${ }^{1}$ Interview with fund manager, Robert Stansky, reported in Magellan Fund Semi-Annual Report, September 30, 2005.
} 
After underweighting energy versus the index during the first half of the period, I increased the fund's exposure to a significant overweighting during the summer months... Another change I made was raising the fund's weighting in reinsurance stocks... Conversely, I trimmed selected positions in the industrials and consumer discretionary sectors.

Jason Weiner, Portfolio Manager of Fidelity Independence Fund ${ }^{2}$

Industry factors capture an economically important component of the variation in security returns (Cavaglia, Cho and Singer, 2001). Portfolio managers and analysts are industry experts who possess superior ability when it comes to industry-level analysis and recommendations. Evidence of industry acumen is provided by Boni and Womack (2003) who find that analysts are able to signal winning and losing stocks within their industries using upgrade and downgrade recommendations. Further evidence of the importance of industry factors in investment strategy is demonstrated by Kacperczyk, Sialm and Zheng (2003) who examine the impact of industry concentration on the performance of equity mutual funds and find that a concentrated portfolio often performs better than a diversified portfolio.

Managers and analysts emphasize industry decisions and demonstrate industry specific skills, yet the abundance of empirical work devoted to performance evaluation appears to neglect this. This paper contributes to filling the gap, investigating fund managers' ability to time shifts amongst industries. Using a sample of 609 US equity funds over the period 1985 to 2002, we find no selectivity, market or industry timing ability for most funds. Finance, Cyclical Services and Information Technology appear particularly difficult to time, with evidence of repeated perverse timing. Managers are best at timing consumer goods industries. Finally, twenty-one of the funds indicate strong forecasting skills, consistently timing industries other mangers poorly time (Finance, Cyclical Services and Information Technology).

The rest of the paper proceeds with a discussion, followed by data and methodology in Section 3, results and conclusion in Section 4.

\section{Background}

Market timing relies on accurate forecasting of the relative performance of asset classes and adjusting asset allocation to exploit the prediction. Sharpe (1976) uses a simple scenario of switching between t-bills and equities to estimate profitability of and forecasting accuracy required for successful market timing based on historical data and assumptions about frequency, transactions costs, etc. Extending beyond a basic cash/equities model, timers can broaden portfolio composition to other asset classes (bonds, real estate commodities, for example), or to classify and time shifts using other criteria such as: fundamentals (eg, book-to-market ratio, size); industry; geography of listing; type of issuer or quality (eg, blue chip stocks, investment grade bonds). The exercise becomes more complex but the timing strategy is built around the same principle: forecasts of the relative performance of the classes are used to determine allocation or weightings, with the goal of earning returns in excess of a static benchmark.

Most empirical studies of fund managers' timing skill test only for evidence of shifts in equity exposure. The general findings confirm that successful market timing is rare. ${ }^{3}$ More recent studies incorporate enhancements in the methodology. Bollen and Busse (2001) find some evidence of market timing ability using daily, rather than monthly, data. Ferson and Schadt (1996) use conditioning information in their models that result in an improvement in performance but no significant ability is detected.

While majority of market timing studies limit their investigation to timing of the US equity markets, there are numerous examples investigating equity timing in other markets and of other asset classes. Comer (2003) assesses the performance hybrid funds (known as balanced or asset allocation funds) and finds some evidence of stock market timing ability over the 1992 to 2000 period. Chen, Ferson and Peters (2005) are among the first to examine the market timing of fixed income funds. They include conditioning information to control for sources of non-linearity unrelated to timing. The results are similar to previous findings for equity funds, which indicate a concave relation between fund and benchmark returns, indicating "negative" timing skill. Strong evidence of perverse timing between bonds and cash is linked to high expense ratios by Comer, Boney and Kelly (2005).

\footnotetext{
2 Interview with fund manager, Jason Weiner reported in Independence Fund Annual Report, November 30, 2005.

3 See Chang and Lewellen (1984), Lehman and Modest (1987) and Cumby and Glen (1990) who also report evidence of perverse timing ability. Several studies (Hendricksson, 1984; Connor and Korajcyzk, 1991) report an apparent trade-off between timing and selectivity where evidence of negative timing is accompanied by superior security selection.
} 
Sector- or industry-focused studies include Dellva, DeMaskey and Smith (2001) who assess timing ability of sector-focused funds, and conclude that many sector fund managers have high selectivity skills but low timing ability. As national borders fade and capital markets integrate, sector allocation (rotation) strategies become more appropriate and more valuable in global investing than country allocation strategies (Weiss, 1998). Cavaglia, Brightman, and Aked 2000), provide evidence of the increasing importance of global industry factors relative to country factors as determinants of security returns. We extend the investigation by testing for evidence of industry timing ability using data and methodology explained in the following section.

\section{Data and methodology}

Most studies of market timing use a form of the Treynor-Mazuy (1966) model to detect non-linearity in the relationship between portfolio and market returns. ${ }^{4}$ The model is an extended, empirical version of the Capital Asset Pricing Model (CAPM) model and is specified in its basic form as: ${ }^{5}$

$R_{j t}-r_{f t}=\alpha_{j}+\beta_{j}\left(R_{m t}-r_{f t}\right)+\gamma_{j}\left(R_{m t}-r_{f t}\right)^{2}+\varepsilon_{j t}$

where $R_{j t}$ is the return on portfolio $j$ for period $t$,

$R_{m t}$ is the return on the market for period $t$, and

$r_{t}$ is the risk-free return for period $t$.

If a fund manager has the ability to time the increase (decrease) in his fund's market exposure prior to a market upswing (downturn), the portfolio's excess return will be a convex function of the market's excess return and $\gamma_{j}$ will be positive.

For our tests, industry return variables are added to the model to test for timing skill of selected industries:

$R_{j t}-r_{f t}=\alpha_{j}+\beta_{j, I}\left(R_{\mathrm{I}, t}-r_{f t}\right)+\gamma_{j, I}\left(R_{\mathrm{I}, t}-r_{f t}\right)^{2}+\ldots+\beta_{j, I}\left(R_{\mathrm{I}, t}-r_{f t}\right)+\gamma_{j, I}\left(R_{\mathrm{I}, t}-r_{f t}\right)^{2}+\varepsilon_{j, t}$

where $R_{j t}$ is the return on portfolio $j$ for period $t$,

$R_{I n, t}$ is the return on industry $I_{n}$ for period $t$, and

$r_{t}$ is the risk-free return for period $t$.

The portfolio's excess return is regressed on various industries' excess returns. Positive coefficients $\gamma_{j, I}$ indicate the ability to time the increase (decrease) in the fund's exposure to a given industry $I$, prior to a market upswing (downturn).

The data used in this study are from the Bloomberg and Datastream databases. The Datastream industry indices are based on the FTSE Classification System. A market (country) index is classified as Level 1. Each market is then broken down into sectors on a number of levels, each level offering an increasing focus. Using Level 3 classification, we use ten industries: 1. Resources, 2. Basic Industries, 3. Cyclical Consumers, 4. Non Cyclical Consumers, 5. Cyclical Services, 6. NonCyclical Services, 7. Utilities, 8. Information Technology, 9. Finance and 10. General Industries. A graphical presentation of industries' and market's returns characteristics is shown in Graph 1.

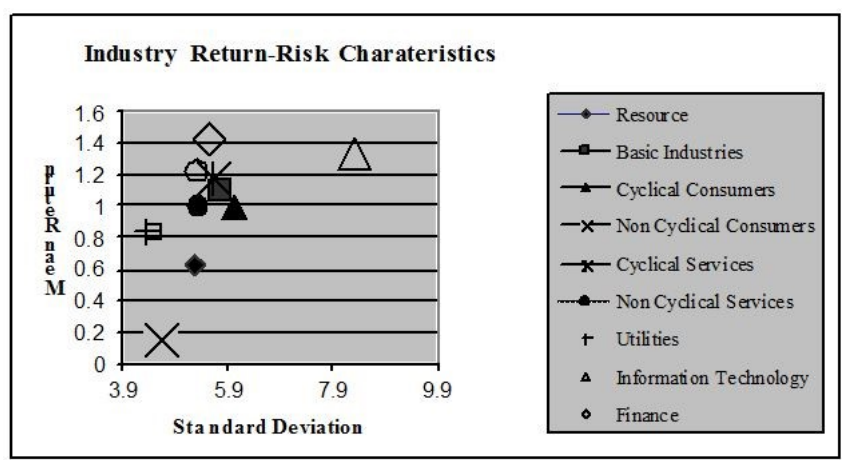

Graph 1: Industry and market returns

The Bloomberg database is used to identify actively managed US equity funds with 'Aggressive Growth', 'Income and Growth' and 'Growth' as investment objectives. Special care is taken to exclude any index or industryspecific funds. The sample comprises open-ended funds spanning the time of March 1985 to December 2002, with a minimum three-year performance history. On average, a typical fund in our 609 funds sample has 8 and

4 This model is explained in the following section, "Data and Methodology". Recently researchers are applying Sharpe's (1992) style factor model, see Comer (2006).

5 The timing model extends Jensen's (1968) model for selectivity which is based on CAPM: $R_{j t}-r_{f t}=\beta_{j}\left(R_{m t}-r_{f t}\right)$ where $R_{j t}-$ $r_{f t}$ is the excess return earned on portfolio $j$, and $R_{m t}-r_{f t}$ is the market risk premium. The ability to generate returns greater than expected by $\beta_{j}\left(R_{m t}-r_{f t}\right)$ will result in a significant intercept $\alpha j$ when regressing fund returns on market returns $R_{j t}-r_{f t}=$ $\alpha j+\beta_{j}\left(R_{m t}-r_{f t}\right)+\varepsilon_{j t}$ 
half years (104 months) of data. Expenses, fund charges and management fees are ignored, allowing the evaluation to focus on timing and selectivity skills. Fund, industry, and S\&P500 index market returns are from Datastream. The risk-free rate is the secondary market 3-month Treasury Bill Yield annualized using a 360-day year quoted on discount basis from February 1985 to December 2002. Table 1 reports the mean and standard deviation of the funds and the indices. This table reports descriptive statistics of the distribution of monthly returns, 1985 to 2002.

Table 1. Fund and index summary statistics

\begin{tabular}{lrr}
\hline & \% Mean Return & Standard Deviation \\
\hline Funds (N =609) & 1.11 & 27.7 \\
Industry Indices & & \\
Resources & 0.63 & 5.27 \\
Basic Industries & 1.09 & 5.78 \\
Cyclical Consumer & 0.99 & 6.02 \\
Non-Cyclical Consumer & 0.15 & 4.62 \\
Cyclical Services & 1.18 & 5.61 \\
Non-Cyclical Services & 1.00 & 5.3 \\
Utilities & 0.84 & 4.36 \\
Information Technology & 1.33 & 8.35 \\
Finance & 1.42 & 5.53 \\
General Industries & 1.22 & 5.29 \\
S\&P 500 & 0.82 & 4.5 \\
\hline
\end{tabular}

The best performing fund has an average return of $+17.17 \%$ per month while the worst had a $-2.98 \%$ average monthly return. On average, fund return is $+1.11 \%$ per month or $+13.31 \%$ per annum.

\section{Results and interpretation}

We begin by estimating equation (1) using OLS regression. Results of number of funds with significant coefficients is reported in Table 2 . This table reports the number of funds with significant selectivity or timing as indicated by the parameter estimates of the equation:

$R_{j t}-r_{f t}=\alpha_{j}+\beta_{j}\left(R_{m t}-r_{f t}\right)+\gamma_{j}\left(R_{m t}-r_{f t}\right)^{2}+\varepsilon_{j t}$

The intercept $\alpha_{j}$ measures performance above or below risk-adjusted market performance, attributed to stock picking ability. The coefficient $\gamma_{j}$ measures nonlinearity related to the ability to increase or decrease market exposure to correspond with market returns.

Table 2: Selectivity and market timing

\begin{tabular}{lrrr}
\hline Selectivity, $\alpha_{j}$ & Positive & Negative & Nil \\
\hline \# of funds & 10 & 99 & 500 \\
\% of sample & 1.64 & 16.26 & 82.1 \\
Market Timing, $\gamma_{j}$ & & & \\
\# of funds & 29 & 15 & 565 \\
\% of sample & 4.76 & 2.46 & 92.78 \\
\hline
\end{tabular}

@ 5\% significance level

The intercept, $\alpha_{j}$ indicates evidence of selectivity skills, while the coefficient $\gamma_{j}$ tests for evidence of skill in timing the broad equity market. A vast majority of the funds ( $80 \%$ to $90 \%$ ) display neither selectivity nor timing skill. Significant negative selectivity and timing parameter estimates are more prevalent than positive estimates, and fund managers seem to be better at timing markets than at selecting stocks. Ten (1.64\%) of the funds display selectivity skill and $29(4.8 \%)$ have positive timing coefficients at a $5 \%$ significance level. A summary of the results of the industry timing tests using Equation (2) are reported in Table 3. This table reports the number of funds with significant timing coefficients $\gamma_{j, I}$ estimated with the equation:

$R_{j \mathrm{t}}-r_{\mathrm{ft}}=\alpha_{\mathrm{j}}+\beta_{\mathrm{j}, \mathrm{I}}\left(\mathrm{R}_{\mathrm{I}, \mathrm{t}}-\mathrm{rft}_{\mathrm{ft}}\right)+\gamma_{\mathrm{j}, \mathrm{I}}\left(\mathrm{R}_{\mathrm{I}, \mathrm{t}}-\mathrm{rft}^{2}\right)^{2} . .+\beta_{\mathrm{j}, \mathrm{I}}\left(\mathrm{R}_{\mathrm{I}, \mathrm{t}}-\mathrm{r}_{\mathrm{ft}}\right)+\gamma_{\mathrm{j}, \mathrm{I}}\left(\mathrm{R}_{\mathrm{I}, \mathrm{t}}-\mathrm{r}_{\mathrm{ft}}\right)^{2}+\varepsilon_{\mathrm{j} \mathrm{t}}$

The coefficients $\gamma_{j, I}$ measure nonlinearity related to the ability to increase or decrease exposure industry $I$ to correspond with industry returns. 
Table 3: Industry timing performance

\begin{tabular}{lrrrrrrr}
\hline & & & \multicolumn{5}{c}{ Number of Industries } \\
\hline Positive Timing & 0 & 1 & 2 & 3 & 4 & 5 & Total \\
\hline significant @ 5\% & 438 & 148 & 19 & 3 & 1 & 0 & 609 \\
significant @ 10\% & 345 & 200 & 51 & 9 & 4 & 0 & 609 \\
\hline Negative Timing & 0 & 1 & 2 & 3 & 4 & 5 & Total \\
\hline significant @ 5\% & 437 & 146 & 23 & 3 & 0 & 0 & 609 \\
significant @ 10\% & 324 & 196 & 72 & 13 & 5 & 0 & 609 \\
\hline
\end{tabular}

Majority of the fund managers are unable to time any industry, both at the five- and ten-percent significance levels. Those demonstrating perverse timing (negative timing coefficients, indicating that they increase (decrease) exposure in down (up) markets) outnumber those with positive timing ability.

Table 4 reports the number of funds with significant timing coefficients by industry. This table reports the number and proportion of funds with significant timing skill in each industry. Significance level is $5 \%$.

Table 4: Significant timing by industry

\begin{tabular}{rrrrrrrrrrr}
\hline \multicolumn{1}{c}{} & \multicolumn{1}{c}{ Most Frequent } & & & & & \multicolumn{2}{c}{ Positive Industry Timing } \\
Least Frequent
\end{tabular}

Fund managers are best at timing the Cyclical Consumer Goods sector both at five- and ten-percent significance, with the highest number of positive timing coefficients and lowest number of negative timing coefficients. The Finance industry appears especially difficult to time, with a low frequency of positive timing coefficients and highest frequency of negative timing coefficients. In addition, managers are unable to time Cyclical Services industry. Non Cyclical Services' industry is the least frequently timed industry, either positively or negatively, suggesting that fund managers have no timing ability at all when investing in this industry.

The detailed results show that fund managers often have an ability to positively time one industry, while negatively timing another industry. An investigation is taken into the pervasiveness of this effect using the matrix reported in Table 5. This table reports the number of funds with significant timing @5\% in none to four industries.

Table 5: Frequency of combined timing skills

\begin{tabular}{lrrrrrr}
\hline Negative & \multicolumn{5}{c}{ Positive Industry Timing } & Total \\
\cline { 2 - 7 } Industry Timing & 0 & 1 & 2 & 3 & 4 & \\
\hline 0 & 334 & 88 & 13 & 2 & 0 & 437 \\
1 & 90 & 50 & 6 & 0 & 1 & 146 \\
2 & 12 & 10 & 1 & 0 & 0 & 23 \\
3 & 2 & 0 & 0 & 1 & 0 & 3 \\
4 & 0 & 0 & 0 & 0 & 0 & 0 \\
Total & 438 & 148 & 19 & 3 & 1 & 609 \\
\hline
\end{tabular}

Evidence of neither negative nor positive timing abilities is found for about half of the funds (334). Approximately eighteen percent (103) of the funds display positive timing of one or more industries and no negative timing coefficients. The proportion is similar for funds displaying negative timing of one or more industries and no positive timing coefficients. The tendency for perverse timing is similar to evidence of positive industry timing abilities with about eighteen percent recording more negative (positive) timing than positive (negative) industry timing.

Further investigation is taken into the 171 funds that positively time at least one industry (regardless of the number of industries it negatively timed). Of these funds, there is a class of fifteen funds showing positive timing in two or more industries, without any negative industry timing. Upon further analysis, we find that funds in this superior class are able to correctly time the industries that the others would otherwise poorly time. In Table 6 
we compare the industry timing patterns of the fifteen funds with that of the other positive timers. This table reports the patterns of timing success by industry of the funds exhibiting positive timing skills. The star funds exhibit positive timing in 2 or more industries @ $5 \%$ and no negative timing.

Table 6: Timing frequency of superior funds

\begin{tabular}{lrrrrrrr}
\hline & & & & & & Industry \\
\hline & $\begin{array}{r}\text { Non Cy } \\
\text { Services }\end{array}$ & $\begin{array}{r}\text { Cyclical } \\
\text { Services }\end{array}$ & Finance & Resource & $\begin{array}{r}\text { Info } \\
\text { Tech }\end{array}$ & Utilities & General \\
\hline Stars & 1 & 2 & 6 & 4 & 5 & 6 & 8 \\
Positive Timing & 1 & 6 & 7 & 7 & 9 & 15 & 19 \\
$\%$ & 100 & 33.3 & 85.7 & 57.1 & 55.5 & 40.0 & 42.1 \\
\hline
\end{tabular}

At 5\% significance, their skills are primarily in timing Non-Cyclical Services, Finance, Information Technology and Resources we note that Non-Cyclical Services, industries that are least frequently correctly timed by fund managers (Table 4). We thus conclude that there exists a class of industry timing experts who possess superior forecasting abilities and are able to consistently time industries that would otherwise be poorly timed.

\section{Conclusion}

A very important fund management activity is a strategy of adjusting industry exposure based on outlook for industry conditions, yet performance evaluation in the academic literature has ignored this. This study measures industry timing ability of 609 actively managed US funds from 1985 to 2002. We find that negative industry timing occurs as frequently and positive industry timing at a five-percent significance level, where the thirty-six percent of funds is split approximately evenly. Negative timing is more common than positive industry timing at ten-percent level of significance, with thirty percent displaying negative timing and twenty-three percent displaying positive industry timing.

Repeated perverse timing appears in the Finance, Cyclical Services and Information Technology industries, while best timing occurs in the Cyclical Consumer Goods and Non-Cyclical Consumer Goods industries. We also find a set of fifteen-star fund managers that demonstrate strong forecasting abilities, positively timing two or more industry and no industries mistimed. They consistently time industries (Finance, Non-Cyclical Services and Information Technology) that most fund managers usually time poorly.

Our analysis of industry timing ability extends the previous studies of market and style timing by focusing on the skill of fund managers to tilt their portfolio exposure towards (away from) industries expected to do well (poorly) and offer a new perspective on the evaluation of fund managers to the investment community.

\section{References}

Bollen, N. P. and J. A. Busse, "On the Timing Ability of Mutual Fund Managers." Journal of Finance 56, 1075-1094, (2001). https://doi.org/10.1111/0022-1082.00356

Boni, L. and K.L. Womack, "Wall Street Research: Will New Rules Change Its Usefulness?" Financial Analysts Journal 59, 25-29, (2003). https://doi.org/10.2469/faj.v59.n3.2528

Cavaglia, S., C. Brightman and M. Aked, "The Increasing Importance of Industry Factors." Financial Analysts Journal 56, 41-54, (2000). https://doi.org/10.2469/faj.v56.n5.2389

Cavaglia, S., D. Cho and B. Singer, "Risks of Sector Rotation Strategies." Journal of Portfolio Management 28, 2435 (2001). https://doi.org/10.3905/jpm.2001.319811

Chang, E. and W. Lewellen, "Market Timing and Mutual Fund Performance." Journal of Business 57(1), 57-72, (1984). https://doi.org/10.1086/296224

Chen Yong, W. Ferson and H. Peters, "The Timing Ability of Fixed Income Mutual Funds." Working paper, Boston College, (2005).

Comer, G., "Hybrid Mutual Funds and Market Timing Performance." Journal of Business 79, 771-798, (2006). https://doi.org/10.1086/499137

Comer G., V. Boney and L. Kelly, "High Quality Bond Funds: Market Timing Ability and Performance." Working paper, Georgetown University, (2005).

Cumby. R. E. and J. D. Glen, "Evaluating the Performance of International Mutual Funds." Journal of Finance 45, 497-521, (1990). https://doi.org/10.1111/j.1540-6261.1990.tb03700.x

Dellva, W., A.L. DeMaskey and C.A. Smith, "Selectivity and Market Timing Performance of Fidelity Sector Mutual Funds." The Financial Review 36, 39-54, (2001). https://doi.org/10.1111/j.1540-6288.2001.tb00003.x 
Ferson, W. and R. Schadt, "Measuring Strategy and Performance in Changing Economic Conditions." Journal of Finance 51, 425-462, (1996). https://doi.org/10.1111/j.1540-6261.1996.tb02690.x

Jensen, M.C., "The Performance of Mutual Funds in the Period 1945-1964." Journal of Finance 23, 389-416, (1968). https://doi.org/10.1111/j.1540-6261.1968.tb00815.x

Kacperczyk, M., C. Sialm and L. Zheng, "On the Industry Concentration of Actively Managed Equity Mutual Funds" Journal of Finance, forthcoming. https://doi.org/10.1111/j.1540-6261.2005.00785.x

Lehman, B. N. and D. M. Modest, "Mutual Fund Performance and Evaluation: A Comparison of Benchmarks and Benchmark Comparisons." Journal of Finance 42, 233-265, (1987). https://doi.org/10.1111/j.15406261.1987.tb02566.x

Sharpe, W.F., "Mutual Fund Performance." Journal of Business 39(1), 119-138, (1966). https://doi.org/10.1086/294846

Sharpe, W.F., "Likely Gains From Market Timing." Financial Analysts Journal 31, 60-69, (1975). https://doi.org/10.2469/faj.v31.n2.60

Sharpe, W.F., "Asset Allocation: Management Style and Performance Measurement." Journal of Portfolio Management 18, 7-19 (1992). https://doi.org/10.3905/jpm.1992.409394

Treynor, J.L. and K. Mazuy, "Can Mutual Funds Outguess the Market?" Harvard Business Review 45, 131-136, (1966).

Weiss, R. A., "Global Sector Rotation: New Look at an Old Idea." Financial Analysts Journal 54, 6-8, (1998). https://doi.org/10.2469/faj.v54.n3.2175 